\title{
Experimental study on fiber mortar strength at early age under temperature difference
}

\author{
Yan Zhang ${ }^{1, a}$ and Ning Li ${ }^{2}$ \\ ${ }^{1}$ School of civil engineering and architecture, Xi' an University of Science and Technology, Xi' an, Shaanxi 710054, China \\ ${ }^{2}$ Institute of Geotechnical Engineering, Xian University of Technology, Xi' an, Shaanxi 710048, China
}

\begin{abstract}
The condition of high temperature is easy to destroy the concrete structure of tunnels. Many temperature difference conditions are applied to ordinary mortar and fiber mortar specimens, the early strength values of mortar caused by temperature change were measured. The flexural strength change rules of the specimens were analysed. The influence of temperature difference on different specimens, and the cause of the strength difference and failure of the specimens are studied. It provides experimental basis for improving the service life of high temperature tunnel cement concrete structure.
\end{abstract}

\section{Introduction}

Temperature difference in high temperature tunnels is a geological phenomenon which can be frequently encountered in engineering. According to the structural characteristics of concrete, the condition of high temperature difference creates the condition for the large number of early cracks in concrete ${ }^{[1-3]}$. Research shows ${ }^{[4-6]}$, at early age when the strength is low, under the action of early temperature stress and dry shrinkage stress etc., the probability of micro cracks in concrete will increase greatly. At the same time, the early performance of concrete changes significantly, and cracks are generated easily. Early stage concrete is affected obviously by temperature and the hydration will be accelerated ${ }^{[7,8]}$. Temperature will eventually affect the strength of concrete. When the tensile stress exceeds the tensile strength of the concrete, the structure will $\operatorname{crack}^{[9,10]}$. At present, the formation and expansion of cracks in early concrete structures are difficult to predict.

A number of experimental results showed that the tensile strength of concrete at high temperatures had an increasing influence on its structural bearing capacity ${ }^{[11-}$ ${ }^{14]}$. In this paper, the tensile strength of sprayed concrete was studied by the flexural strength of the specimen. According to the temperature difference state of the cement concrete spray layer, the tensile strength tests of mortar specimens under different temperature difference conditions were carried out. Therefore, the early mechanical properties of cement mortar under different high temperature differential conditions can be investigated.

\footnotetext{
a Yan Zhang: ylozy@126.com
}

\section{Experiment scheme}

The cement used in the experiment was the Shaanxi Qinling Mountains ordinary portland cement (PO42.5R), all indicators conform to national standard GB50010$2010^{[15]}$. The mass ratio of sand to cement was set as 1.0 , and four sets of mortar specimens were formed: plain mortar (OM), polyester mortar (PEM), polypropylene mortar (PPM) and polyacrylonitrile mortar (PAM). The fiber content of this sample was $0.9 \mathrm{~kg} / \mathrm{m}^{3}$, as recommended by the manufacturer. The specific material mix ratio of the sample is shown in Table 1. According to fluidity test, the sand rate was adjusted to maintain a certain fluidity $45 \mathrm{~mm}$. The prism of the specimen was $40 \mathrm{~mm} \times 40 \mathrm{~mm} \times 160 \mathrm{~mm}$ and form removal after the initial solidification. Temperature difference heating device, the electrothermal ring (diameter $300 \mathrm{~mm}$, high $100 \mathrm{~mm}$ ) is shown in Figure 1. The temperature of the heating surface can be controlled by an automatic temperature controller, the internal emptying surface is exposed to indoor air at a temperature of $25^{\circ} \mathrm{C}$. The temperature of the heating surface of the specimen is controlled at $25^{\circ} \mathrm{C}, 45^{\circ} \mathrm{C}$, $60^{\circ} \mathrm{C}, 80^{\circ} \mathrm{C}, 90^{\circ} \mathrm{C}, 100^{\circ} \mathrm{C}$, respectively. That is to control the temperature difference on both sides at $0^{\circ} \mathrm{C}$, $20^{\circ} \mathrm{C}, 35^{\circ} \mathrm{C}, 55^{\circ} \mathrm{C}, 65^{\circ} \mathrm{C}, 75^{\circ} \mathrm{C}$. Then the molded specimens are maintained to the designated $3 \mathrm{~d}$ and $7 \mathrm{~d}$ age and taken out and the flexural strength were measured separately. When measuring, the direction of temperature difference is consistent with the loading direction.

The test circuit includes electric heating coil, temperature probe, temperature controller, overcurrent protection circuit opener and $\mathrm{AC}$ contactor. It also 
includes DH3816 strain tester which can measure strain and the corresponding computer to collect the strain data of other subsequent tests. Flexural strength is determined by cement mortar flexural strength testing equipment DKZ-5000. When the bearing capacity of the specimen is reduced to $85 \%$ of the peak load, it is considered as the specimen failure.

Table 1. The proportioning of the mortar specimens.

\begin{tabular}{|c|c|c|}
\hline Types & $\begin{array}{c}\text { Fiber } \\
\text { content }\end{array}$ & $\begin{array}{c}\text { Cement: water: } \\
\text { sand }\end{array}$ \\
\hline $\mathrm{OM}$ & 0 & \multicolumn{1}{|}{} \\
\hline $\mathrm{PEM}$ & $0.9 \mathrm{~kg} / \mathrm{m}^{3}$ & \multirow{2}{*}{$1: 0.52: 3$} \\
\hline $\mathrm{PPM}$ & $0.9 \mathrm{~kg} / \mathrm{m}^{3}$ & \multicolumn{1}{|}{} \\
\hline $\mathrm{PAM}$ & $0.9 \mathrm{~kg} / \mathrm{m}^{3}$ & \\
\hline
\end{tabular}

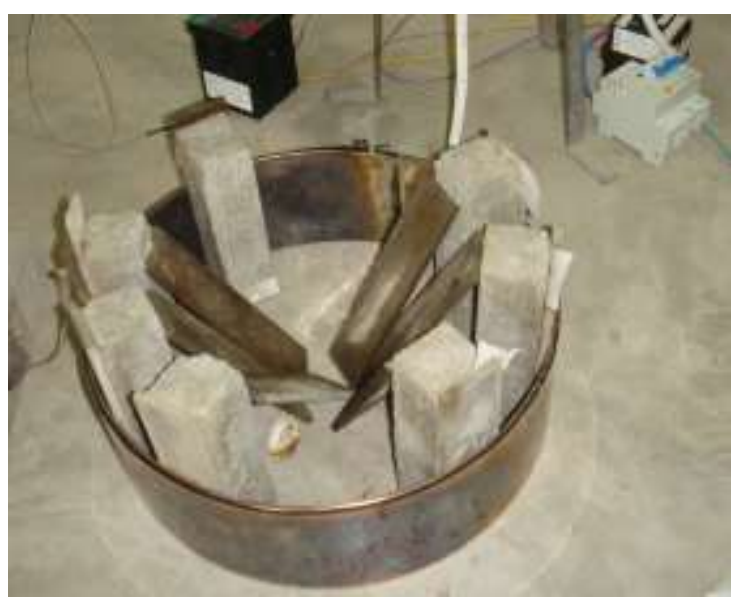

Figure 1. Temperature differences curing device for samples.

\section{Results and analysis}

The flexural strength curves of mortar specimens with different temperature difference at early age are shown in figures 2 and 3. The flexural strength values of all kinds of mortar at different temperatures are shown in figures 4 and 5 .

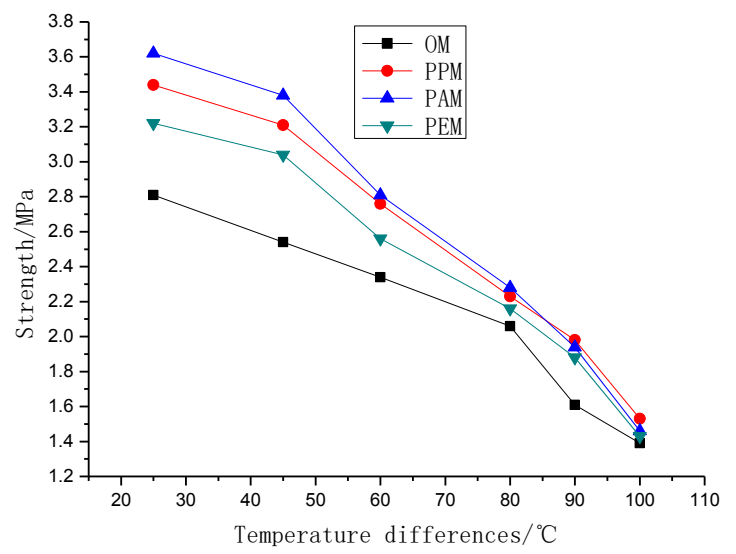

Figure 2. Variation curves of flexural strength of 3 days mortar with temperature differences.

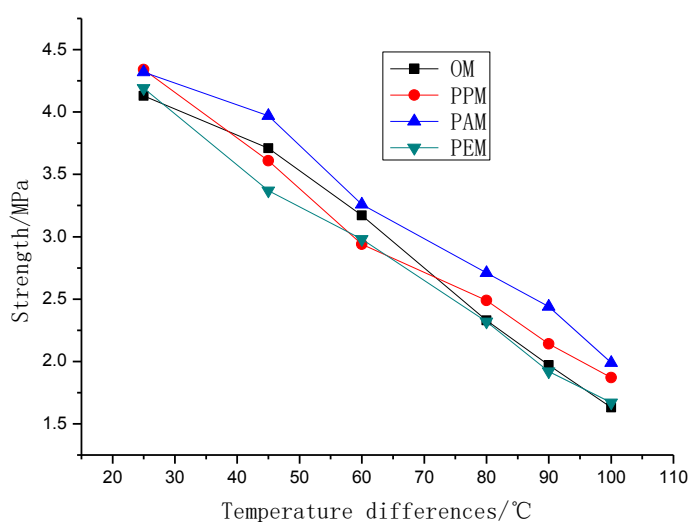

Figure 3. Variation curves of flexural strength of 7 days mortar with temperature differences.

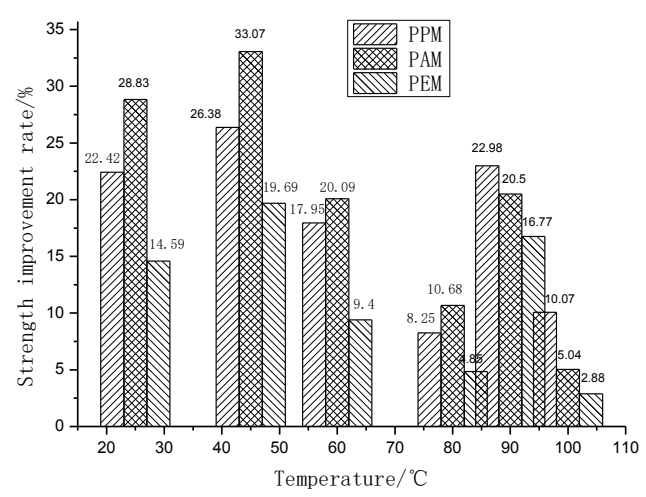

Figure 4. Flexural strength growth rate of 3 days mortar with temperature differences.

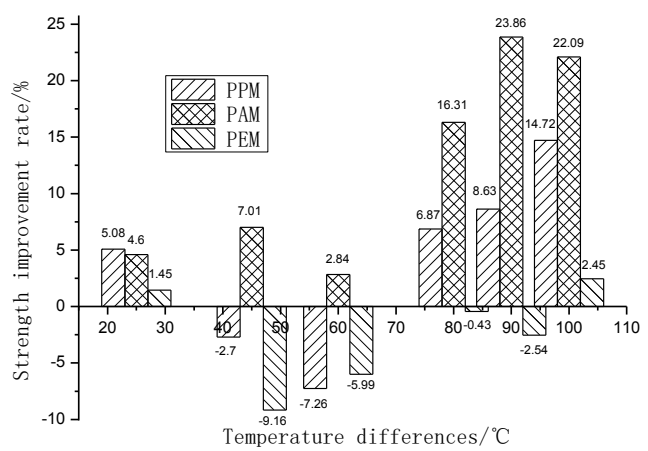

Figure 5. Flexural strength growth rate of 7 days mortar with temperature differences.

It can be seen from figures 2 and 3 that the flexural strength of early-age mortar specimens decreases with the increasing temperature difference. The reduction of fiber mortar flexural strength is smaller than plain mortar under temperature difference. It indicates that the fiber 
can help to alleviate the impact of temperature difference on the flexural strength of mortar.

It can be seen from figure 4 that the flexural strength of fiber mortar specimens is greater than that of plain mortar at the age of $3 \mathrm{~d}$ during every temperature range, and the fiber has begun to play a role in the early stage of cement-based mortar. When the temperature difference is $20^{\circ} \mathrm{C}$, the flexural strength of polyacrylonitrile fiber mortar is greater than the plain cement mortar by $33 \%$. Compared to plain cement mortar, the flexural strength of polyacrylonitrile fiber mortar increased by $21 \%$ and $11 \%$ respectively when the temperature difference between $35^{\circ} \mathrm{C}$ to $55^{\circ} \mathrm{C}$. When the temperature difference is $65^{\circ} \mathrm{C}$, the flexural strength of polypropylene fiber mortar is higher than the plain mortar by $21 \%$. When the temperature difference is $75^{\circ} \mathrm{C}$, the flexural strength of polypropylene fiber mortar is higher than the plain mortar by $11 \%$. The effect of polyester fiber on the flexural strength is minimal. It can be seen that the incorporation of fibers will increase the flexural strength of mortars at temperature difference. The smaller the temperature difference, the smaller the effect on flexural strength of mortars degradation, and the less obvious the effect of fibers.

As shown in figure 5, the flexural strength of all mortars at the age of 7 days decreases with the increasing temperature difference, and the reduction rate of the flexural strength is higher than the mortars at the age of $3 \mathrm{~d}$. The greatest reduction of the flexural strength is plain mortar. Compared with plain cement mortar, the flexural strength of polyacrylonitrile fiber mortar increased by $5 \%$, $7 \%, 3 \%, 7 \%, 24 \%$ and $22 \%$, respectively when the temperature difference is $20^{\circ} \mathrm{C}, 35^{\circ} \mathrm{C}$ and $55^{\circ} \mathrm{C}$, $65^{\circ} \mathrm{C}$ and $75^{\circ} \mathrm{C}$. Only when the temperature difference is $20^{\circ} \mathrm{C}$, the flexural strength of polypropylene fiber mortar is higher than that of polyacrylonitrile mortar by $5 \%$, and the flexural strength at other temperatures is not as strong as polyacrylonitrile mortar. When the temperature differences are $20^{\circ} \mathrm{C}$ and $35^{\circ} \mathrm{C}$, the flexural strength of polypropylene, polyester fiber mortar are less than that of plain cement mortar. It can be seen that polyacrylonitrile fiber mortar in the long age under high temperature conditions has better stability. In general, the greater the temperature difference, the more serious the strength degradation of the specimens. With increasing age, the influence of temperature difference is greater. Temperature difference restricts the growth rate of mortar strength. The greater the temperature difference, the slower the strength growth of mortar specimens in the same time period.

\section{Conclusion}

The flexural strength of four types of specimens (OM, PEM, PPM, PAM) under temperature differences were investigated. And the experimental results provide a reference for the stability analysis of high temperature tunnels. Based on the relevant results, the following conclusions can be drawn:
1) Through the mortar test under the condition of the temperature difference, the influence rule of flexural strength of mortar at early ages under temperature difference was obtained. Furthermore, the earlier the mortar strength age, the more obviously affected by temperature difference.

2) With the experimental data, the strength change curve of the mortar specimen at different temperature difference is plotted. The results show that the temperature difference has a deterioration effect on the mortar strength. The fibers in mortar can improve the degradation of the flexural strength and play a certain role in alleviating the degradation. The adhesion between fiber and cement matrix prevents the crack from spreading.

3) At the same age, the greater the temperature difference is, the greater the reduction of the strength of the mortar specimen will seriously affect the stability of the cement concrete structure of the high-temperature tunnel. The temperature difference should be solved as far as possible in practical engineering.

\section{Acknowledgements}

The study was sponsored by the National Natural Science Foundation of China (Grant No. 51509200), the Nurturing Foundation of Xi'an University of Science and Technology (Grant No. 6310214036) and the Doctoral Foundation of Xi'an University of Science and Technology (Grant No. 6310115020).

\section{References}

1. Z.H. Guo, X.D. Shi, Behaviour of reinforced concrete at elevated temperature and its calculation. Beijing: Tsinghua University Press(2002)

2. J.C. Guo, J.T.Yu, Z.D.Lu, Industrial construction. 38, 9(2008)

3. Y. Li, X. Liu, M. Wu, Const. Build. Mater.34, (2017)

4. S. Lepage , M. Baalbaki, É. Dallaire, P.C. AïTcin, Cement, Concrete and Aggregates, 21,2(1999)

5. X.Y. Jin, Y.Tian, N.G. Jin , Journal Of Building Structures, 31,6(2010)

6. E. Tazawa. Autogenous shrinkage of concrete. London: Great Britain, St Edmundsbury Press(1998)

7. I. Khan, A.Castel, R.I.Gilbert, ACI Mater. J., 114, 4 (2017)

8. I.Pane, W.Hansen, Mater. Struct., 35, 2 (2002)

9. S.Altoubat, M.T.Junaid, M.Leblouba, D.Badran, Cem. Concr. Compos., 79(2017)

10. J.Xin, G.Zhang, Y.Liu, Z.Wang, Wu Z., Constr. Build. Mater., 192 (2018)

11. Y.Ding, C.Zhang, M. Cao, Construction and Building Materials, 113,15(2016)

12. B.Chen, J.Liu, Cement and Concrete Research, 34, 6(2004)

13. P. Kalifa, G. Chéné, C. Gallé, Cement \& Concrete Research, 31, 10(2001)

14. Y.Ding, C.Azevedo, J. Aguiar, S. Jalali, Construction \& Building Materials, 26, 1(2012) 
15. The National Standards Compilation Group of the People's Republic of China, GB 50010-2010. "Common Portland cement." Beijing: China Standards Press (2015) 